\title{
The Use of Health Technology to Enhance the Adherence of Tuberculosis Treatment: A Systematic Review
}

\section{Dwi Uswatun Sholikhah, Gevi Melliya Sari, Cahya Mustika Narendri, Sariati Sariati and Nora Dwi Purwanti}

Faculty of Nursing, Universitas Airlangga, Surabaya, Indonesia

\begin{abstract}
Introduction: Disobedience in the context of TB treatment is one of the major problems around the world. Many efforts have been made to improve the adherence to TB treatment; one of them is the utilization of health technology such as digital technology. The aim of the study was to identify the effectiveness of the use of health technology such as digital technology to improve treatment compliance.
\end{abstract}

Methods: The literature review was used to identify the interventions and then the identification of the relevant literature was done by topic and title, obtaining the literature in full text form. The analysis of the results was drawn from the many interventions in the literature. There were 15 articles found from the systematic search performed in the Scopus, Proquest, Science direct, Spingerlink and Sage databases with an RCTs design. This was conducting by entering the keywords of adherence, promoting adherence, improving adherence, tuberculosis treatment, chronic disease, health technology, digital technology, mhealth and self-reminders.

Results: The search was limited to journals from 2013 to 2018, with the inclusion criteria being the use health technology such as digital technology to improve the adherence to chronic disease treatment (TB treatment).

Conclusion: There are several uses of health technology when it comes to improving the adherence to TB treatment that can be used as a promotive and preventive effort during the treatment of TB.

\section{ARTICLE HISTORY}

Received: Dec 26, 2019

Accepted: Dec 31, 2019

\section{KEYWORDS}

biomedical technology; medication adherence; tuberculosis therapy

\section{CONTACT}

Gevi Melliya Sari

$\triangle$ gevi.melliya.sari2018@fkp.unair.ac.id

$\fallingdotseq$ Faculty of Nursing, Universitas Airlangga, Surabaya, Indonesia

Cite this as: Sholikhah, D. U., Sari, G. M., Narendri, C. M., Sariati, S., \& Purwanti, N. D. (2019). The Use of Health Technology to Enhance the Adherence of Tuberculosis Treatment: A Systematic Review.Jurnal Ners, 14(3si), 65-70. doi:http://dx.doi.org/10.20473/in.v14i3(si).16982

\section{INTRODUCTION}

Disobedience on chronic disease treatment like on TB treatment, is a major problem around the world. Patient with TB are expected to have an adherence rate of more than $90 \%$ to support healing process. The failure of the healing process caused progression risk of disease such as medicine resistance, and continuity of disease transmission in community. These may cause the rise of morbidity and mortality (Adane, Alene, Koye, \& Zeleke, 2013).

Tuberculosis remains the biggest problem in the world. The disease causes illness in 10 million people each year and it is one of the top ten causes of mortality in the worldwide (World Health Organization, 2017). In 2015, the new cases of TB were estimated to be around 10,4 million globally, of which 5,9 million (56\%) were men, 3,5 million (34\%) were women and 1,0 million (10\%) were children (WHO, 2016). In 2016, the incidence rate of TB did not experience a decline and remained the same at10,4 million (around 8,8 million to 12,2 million cases). There were around 140 cases per 100.000 populations. Most estimates of the number of cases in 2016 occurred in Southeast Asia (45\%), Africa (25\%), the Western Pacific Region (17\%), the Eastern Mediterranean (7\%), Europe (3\%) and America (3\%). The 4 countries that have the largest incidence rate in 
the world are India, Indonesia, China and the Philippines (World Health Organization, 2017).

The high incidence rate of $\mathrm{TB}$ is caused by unsuccessful TB treatment which is related to the adherence of TB treatment. The long treatment duration (6 months), the medication side effects, maladaptive coping mechanisms, social and economic factors, and the presence of stigma may affect the adherence of TB treatment. Adherence to the treatment is very important, because when the treatment process is completed with good adherence, it can be very effective at preventing medicineresistant $\mathrm{TB}$, thus curing the disease and preventing the transmission of the disease to others (Guixcomellas et al., 2017).

There are many steps that can be taken to improve the adherence to TB treatment: (1) helping clients deal with social problems that might hinder their abilities during the treatment process, (2) to increase effective cooperation and communication between the care workers and (3) the supervision of the clients directly and indirectly through PMO, through the care workers and through the family who act as Self Reminders for the clients (Oren, Bell, Garcia, PerezVelez, \& Gerald, 2017). These steps can be realized with the existing innovations that are accessible, convenient, flexible and able to empower the clients. One of the utilizations of health technology is in the form of digital technology. The use of digital technology is considered to improve the adherence to a treatment program for the patients of TB. The purpose of this systematic review was to identify health-related digital technology that can be used to improve the adherence to TB treatment. The method used to prepare the systematic review consisted of (1) the identification of interventions in the literature, (2) the identification of the relevant literature by topic and title, (3) obtaining the literature in full text form and (4) the analysis of the results from many interventions in the literature.

\section{MATERIALS AND METHODS}

This paper reported about the interventions used to improve the treatment adherence of patients with TB. The study adopted the systematic review methodology to clarify how diverse digital technology can be used to improve the adherence of TB patients. This paper reported on the first stage of the systematic review from a range of 1824 studies that were obtained by keyword searching. After the removal of duplicates and irrelevant studies, 35 studies that were full text articles were identified and then 20 studies were excluded due to not meeting the inclusion criteria. The remaining 15 randomized studies were considered in this review. The focus of this review was digital technology. The total respondents in this review consisted of 5,013 people with chronic disease (tuberculosis, HIV, asthma) that required adherence to long-term treatment. The research area was in the hospital and in the community.

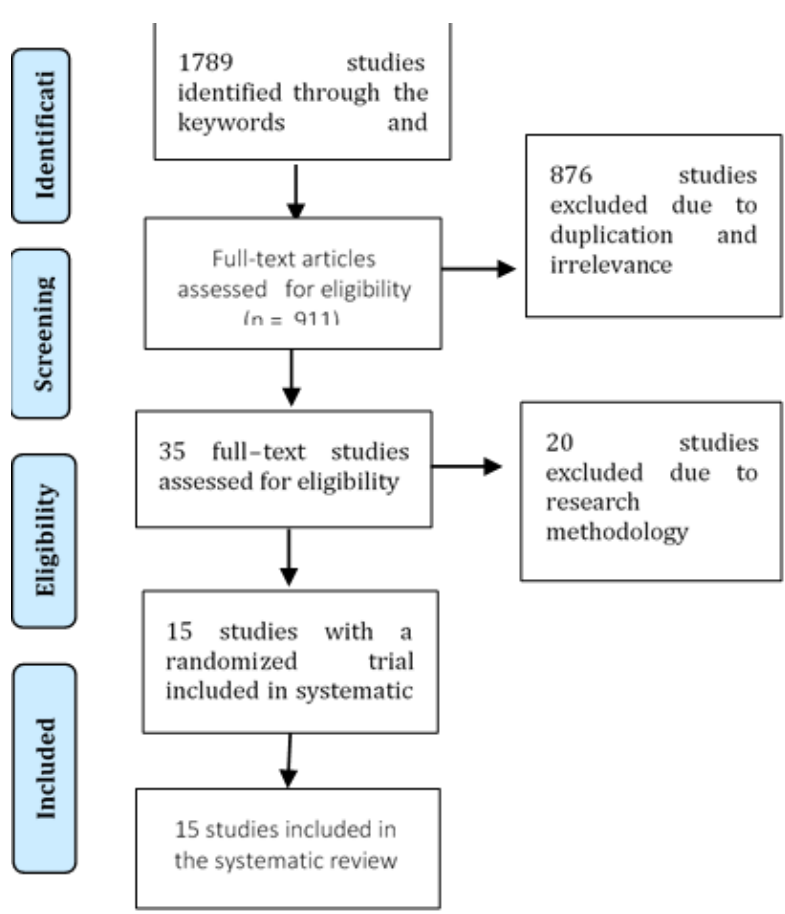

Figure 1. Flow diagram

Literature searches were conducted in multiple databases such as Proquest, Scopus, Sciencedirect, Spingerlink and Sage by entering the keywords of adherence, promoting adherence, improve adherence, tuberculosis treatment, chronic disease, health technology, digital technology, m-health and self-reminders.

The criteria used to include and exclude studies were defined and applied to the set of 1824 studies that were written in English. The criteria of the participants in this study were that they were people with a chronic disease who required long-term treatment, as adherence is necessary during the process of treatment. The use of health technology to improve the adherence to treatment within a longterm intervention period was therefore the focus. A given intervention such as SMS reminders, videoobserved treatment, electronic reminders, mobile interactive supervised therapy or electronic monitoring devices were used to increase adherence in the treatment process. In this review, three articles did not have a comparison intervention. We limited the search range to 5 years (2013 to 2018) with the inclusion criteria being the use of health technology such as digital technology to improve the adherence to chronic disease treatment (TB treatment). The design of the studies were Randomized Controlled Trial Study (RCTs), including cluster RCTs and quasiRCTs. There was no age limitation for the participant in the articles, because the focus of the search was on the chronic disease suffered by the participants.

\section{RESULTS}

Based on the database search, the related studies of this review totaled 15 articles that met the conclusion 
Table 1. The randomized controlled trial studies which were included in the systematic review.

\begin{tabular}{|c|c|c|c|c|}
\hline Author & Type Of Study & Participants & Intervention & $\begin{array}{l}\text { Outcome } \\
\end{array}$ \\
\hline $\begin{array}{l}\text { (Bediang et al., } \\
\text { 2018) }\end{array}$ & RCTs & $\begin{array}{l}297 \text { participants } \\
\text { with TB disease }\end{array}$ & SMS reminder & $\begin{array}{l}\text { The proportion of client recovery } \\
\text { The success of treatment } \\
\text { Adherence to treatment } \\
\text { Control timely }\end{array}$ \\
\hline (Sinkou et al., 2017) & RCTs & $\begin{array}{l}10 \text { participants with } \\
\text { TB disease }\end{array}$ & $\begin{array}{l}\text { Video-observed } \\
\text { treatment }\end{array}$ & Adherence to treatment \\
\hline (Fang et al., 2017) & RCTs & $\begin{array}{l}350 \text { participants } \\
\text { with TB disease }\end{array}$ & SMS reminders & $\begin{array}{l}\text { Complete treatment } \\
\text { Adherence to treatment }\end{array}$ \\
\hline $\begin{array}{l}\text { (Mohammed et al., } \\
\text { 2016) }\end{array}$ & RCTs & $\begin{array}{l}2.207 \text { participants } \\
\text { with TB disease }\end{array}$ & SMS reminders & $\begin{array}{l}\text { The success of the treatment } \\
\text { Self-reported } \\
\text { Adherence to treatment }\end{array}$ \\
\hline $\begin{array}{l}\text { (Johnston et al., } \\
\text { 2018) }\end{array}$ & RCTs & $\begin{array}{l}358 \text { participants } \\
\text { with LTBI }\end{array}$ & SMS reminders & $\begin{array}{l}\text { Completed treatment } \\
\text { Adherence to treatment } \\
\text { Quality of life } \\
\text { Self-reported }\end{array}$ \\
\hline (Liu et al., 2015) & Cluster RCTs & $\begin{array}{l}119 \text { participants } \\
\text { with TB disease }\end{array}$ & $\begin{array}{l}\text { Electronic reminders } \\
\text { (SMS and medication } \\
\text { monitor/MM) }\end{array}$ & $\begin{array}{l}\text { The success of the treatment } \\
\text { Follow up } \\
\text { Adherence to treatment }\end{array}$ \\
\hline $\begin{array}{l}\text { (Iribarren et al., } \\
\text { 2013) }\end{array}$ & RCTs & $\begin{array}{l}37 \text { participants with } \\
\text { TB disease }\end{array}$ & SMS reminders & $\begin{array}{l}\text { Feasibility of the use of the } \\
\text { application } \\
\text { Adherence to treatment } \\
\text { The result of the sputum } \\
\text { examination was negative }\end{array}$ \\
\hline $\begin{array}{l}\text { (Farooqi et al., } \\
\text { 2017) }\end{array}$ & RCTs & $\begin{array}{l}148 \text { participants } \\
\text { with TB disease }\end{array}$ & SMS reminders & Adherence to treatment \\
\hline (Oren et al., 2017) & RCTs & $\begin{array}{l}40 \text { participants with } \\
\text { LTBI }\end{array}$ & $\begin{array}{l}\text { SMS reminders and } \\
\text { phone call reminders }\end{array}$ & $\begin{array}{l}\text { Adherence to treatment } \\
\text { Awareness for control } \\
\text { No loss of medicine dosage }\end{array}$ \\
\hline $\begin{array}{l}\text { (Van Der Kop et al., } \\
\text { 2014) }\end{array}$ & RCTs & $\begin{array}{l}350 \text { participants } \\
\text { with LTBI }\end{array}$ & SMS reminder & $\begin{array}{l}\text { Completed treatment } \\
\text { Adherence to treatment } \\
\text { Treatment is completed on time } \\
\text { Quality of life }\end{array}$ \\
\hline $\begin{array}{l}\text { (Nhavoto et al., } \\
\text { 2017) }\end{array}$ & RCTs & $\begin{array}{l}404 \text { participants } \\
\text { with TB and }\end{array}$ & SMS reminders & $\begin{array}{l}\text { Adherence to treatment } \\
\text { Giving motivation } \\
\text { Health education }\end{array}$ \\
\hline (Molton et al., 2016) & RCTs & $\begin{array}{l}42 \text { participants with } \\
\text { TB disease }\end{array}$ & $\begin{array}{l}\text { MIST (Mobile Interactive } \\
\text { Supervised Therapy) }\end{array}$ & Adherence to treatment \\
\hline (Orrell et al., 2015) & RCTs & $\begin{array}{l}230 \text { participants } \\
\text { with HIV }\end{array}$ & $\begin{array}{l}\text { Electronic monitoring } \\
\text { based on the wisepil } \\
\text { device }\end{array}$ & $\begin{array}{l}\text { Concern for the disease } \\
\text { Adherence to treatment } \\
\text { Decreased viral load }\end{array}$ \\
\hline $\begin{array}{l}\text { (Vasbinder et al., } \\
\text { 2016) }\end{array}$ & RCTs & $\begin{array}{l}219 \text { participants } \\
\text { with asthma }\end{array}$ & $\begin{array}{l}\text { Real Time Medication } \\
\text { Monitoring (RTMM) } \\
\text { using SMS reminders }\end{array}$ & $\begin{array}{l}\text { Adherence to treatment } \\
\text { Control of disease } \\
\text { Quality of life }\end{array}$ \\
\hline (Chan et al., 2015) & RCTs & $\begin{array}{l}220 \text { participants } \\
\text { with asthma }\end{array}$ & $\begin{array}{l}\text { Electronic monitoring } \\
\text { device with an audio- } \\
\text { visual reminder }\end{array}$ & $\begin{array}{l}\text { Adherence to treatment. } \\
\text { Control of disease }\end{array}$ \\
\hline
\end{tabular}

and exclusion criteria. A total of 1824 studies were obtained through the keyword search. After the removal of duplicates and irrelevant studies, 35 studies consisting of full text articles were identified and then 20 studies were excluded due to not meeting the inclusion criteria. The remaining 15 randomized studies were considered in this review. The research explained about digital technology intended to improve adherence for patients with TB. Articles (Bediang, Stoll, Elia, Abena, \& Geissbuhler, 2018), (Fang et al., 2017) (Mohammed, Glennerster, \& Khan, 2016), (Johnston et al., 2018), (Iribarren et al., 2013), (Farooqi, Ashraf, \& Zaman, 2017), (Van Der Kop et al., 2014), (Nhavoto, Gronlun, \& Klein, 2017) explained about the use of SMS reminders, article (Molton et al., 2016) explained about Mobile Interactive Supervised Therapy, article (Orrell et al., 2015) (Liu et al., 2015), explained about the use of electronic monitoring based on the Wisepil device and article (Chan et al., 2015) explained about audio visual devices. Article (Oren et al., 2017) focused on SMS reminders and phone cell reminders, (Vasbinder et al., 2016) explain about real time medication monitoring and article (Sinkou et al., 2017) explained about video observed treatment. The articles awere clarified if the results of the study did not explain the estimated effects of the intervention provided. The steps of the data selection and extraction were as reported in Figure 1.

For each study, the data from the full texts was extracted including publication year, title and the key words, including the authors, research questions, methodology and main results. They were then subject to a thematic analysis focused on the use of digital technology. See on Table 1.

\section{DISCUSSION}

The use of digital technology can help to achieve success in the treatment on a patient with a chronic disease, such as tuberculosis. This chronic condition requires a long-term commitment to the treatment process (Molton et al., 2016). Many studies have been 
conducted to identify whether the use of digital technology is effect at improving medication adherence in clients with chronic disease. For example, through the use of SMS reminders, videoobserved treatments, electronic reminders, mobile interactive supervised therapys and electronic monitoring. In this systematic review, we have discussed the comparison of each intervention given in improving medication adherence.

SMS reminders. Of the 15 articles, there were 8 articles that used SMS reminders as the intervention of their choice. The intervention was carried out by sending a reminder message to the patient according to the prescribed medication time. If the patient does not respond, then a second reminder message will be sent back until the patient responds. The success of the intervention from each article varied; 4 articles explained an increase in TB treatment adherence after being given the intervention and the 4 other articles did not. The failure can be caused by many factors that are limited in the study. For example, the use of SMS reminders that only allows for one-way communication, the inability to verify whether the message really has reached the respondent and the likelihood of the respondents to change their phone number at any time during the research taking place.

SMS reminders and Phone call reminders. Oren's research (2017) explained that, in this study, the TB patients will receive automatic messages from the system containing reminders related to taking the medication. The previous patient's telephone number has been entered into the web platform which later can be used to verify whether the client received the message or not. Each patient is required to respond to the system in response to receiving the reminder message. If the client does not provide a response, then it will continue with a telephone call. The results of the analysis obtained that the use of SMS reminders and phone call reminders can significantly improve the adherence of latent TB patients which is measured by increasing the rate of completion of the treatment, higher self-reporting, reduced doses of the medicine were missing and a shorter treatment.

Video-observed treatment. Video-observed treatments as an intervention were found to improve the treatment adherence of TB patients. Adherence monitoring is done using video calls via a smartphone for each patient. Video monitoring is considered to be more effective at increasing the level of adherence with the TB treatment. In conclusion, 8 of the 10 respondents said that it was more convenient to control via video rather than direct control by going to the clinic (Sinkou et al., 2017).

Electronic reminder (SMS and MM). This intervention uses SMS reminders and communication monitoring (MM) in the form of medicine monitor boxes to improve the adherence of TB patients (Liu et al., 2015). In SMS reminders, the patient will receive a message to take the medication according to a predetermined schedule. The message will be resent if the client does not respond. In addition, the medicine monitor box equipped with an audio device will also sound according to the patient's medication schedule. The medicine monitoring box will not stop ringing until the patient has taken the medicine. Based on the results of the analysis, SMS reminders cannot improve adherence when it comes to taking the TB medicine but medication monitoring in the form of medicine monitoring boxes can significantly improve the adherence to the TB treatment.

MIST (Mobile Interactive Supervised Therapy). MIST is a system consisting of 2 components; web-based and smartphone -based. The web-based component of the system allows for the administrators to manage the time needed to take the medication that is needed every day. This is selected according to the frequency of the therapy and the patient's preferences. After the medication is determined, the system will send a notification for them to take the medication via SMS 30 minutes before the specified schedule with repeated reminders every 15 minutes until the patient sends a video of himself taking the medicine. The video will then be uploaded to the web-based component according to the date and time of taking the medication. If the video has been uploaded successfully, then the video will be automatically deleted from the smartphone. Web-based and smartphone MIST increased the adherence of the TB patients to taking the medicine (Molton et al., 2016).

Real time medication monitoring (RTMM). RTMM is a medication compliance monitoring tool for patients with asthma that is directly linked to the inhaled corticosteroids owned by the patient. This tool will monitor the patient's provisions in relation to taking the medicine accompanied by SMS reminders. The device can improve adherence to the asthma treatment but it cannot control the asthma itself or related exacerbations (Vasbinder et al., 2016).

Electronic monitoring device with audiovisual reminders. There are audiovisual reminders to improve medication adherence in patients with asthma (Chan et al., 2015). The audiovisual reminder consists of 14 audio reminders with different ringtones. The date, time and number of doses of the medicine administration are recorded in the visual display.

\section{CONCLUSION}

The use of health technology such as digital technology provides many benefits, especially in the health sector. For example, for the treatment of chronic diseases such as TB that require long-term treatment, health technology can be used to improve the adherence to taking the TB medicine with a reminder system consisting of SMS reminders, electronic reminders, video-observed treatments, medication monitors and so on. Some health technologies that are used as an effort to improve the adherence to TB treatment can be used as a basis for consideration in the promotion and prevention efforts related to TB. The selection of interventions 
can be adjusted to the objectives that are to be achieved.

\section{REFERENCES}

Adane, A. A., Alene, K. A., Koye, D. N., \& Zeleke, B. M. (2013). Non-Adherence to Anti-Tuberculosis Treatment and Determinant Factors among Patients with Tuberculosis in Northwest Ethiopia, 8(11).

https://doi.org/10.1371/journal.pone.0078791

Bediang, G., Stoll, B., Elia, N., Abena, J. L., \& Geissbuhler, A. (2018). SMS reminders to improve adherence and cure of tuberculosis patients in Cameroon (TB-SMS Cameroon): A randomised controlled trial. BMC Public Health, 18(1), 1-14. https://doi.org/10.1186/s12889-018-5502-x

Chan, A. H. Y., Stewart, A. W., Harrison, J., Camargo, C. A., Black, P. N., \& Mitchell, E. A. (2015). The effect of an electronic monitoring device with audiovisual reminder function on adherence to inhaled corticosteroids and school attendance in children with asthma: A randomised controlled trial. The Lancet Respiratory Medicine, 3(3), 210 $219 . \quad$ https://doi.org/10.1016/S22132600(15)00008-9

Fang, X.-H., Guan, S.-Y., Tang, L., Tao, F.-B., Zou, Z., Wang, J.-X., ... Pan, H.-F. (2017). Effect of Short Message Service on Management of Pulmonary Tuberculosis Patients in Anhui Province, China: A Prospective, Randomized, Controlled Study. Medical Science Monitor, 23, 2465-2469. https://doi.org/10.12659/MSM.904957

Farooqi, R. J., Ashraf, S., \& Zaman, M. (2017). The role of mobile SMS-reminders in improving drugs compliance in patients receiving anti-TB treatment from DOTS program. Journal of Postgraduate Medical Institute, 31(2), 156-162.

Guix-comellas, E. M., Rozas-quesada, L., Morín-fraile, V., Estrada-masllorens, M., Galimany-masclans, J., \& Sancho-agredano, R. (2017). Educational measure for promoting adherence to treatment for tuberculosis. Procedia - Social and Behavioral Sciences, 237(June 2016), 705-709. https://doi.org/10.1016/j.sbspro.2017.02.047

Iribarren, S., Beck, S., Pearce, P. F., Chirico, C., Etchevarria, M., Cardinale, D., \& Rubinstein, F. (2013). TextTB: A Mixed Method Pilot Study Evaluating Acceptance, Feasibility, and Exploring Initial Efficacy of a Text Messaging Intervention to Support TB Treatment Adherence. Tuberculosis Research and Treatment, 2013, 1-12. https://doi.org/10.1155/2013/349394

Johnston, J. C., van der Kop, M. L., Smillie, K., Ogilvie, G., Marra, F., Sadatsafavi, M., ... Lester, R. T. (2018). The effect of text messaging on latent tuberculosis treatment adherence: a randomised controlled trial. European Respiratory Journal, 51(2), 1701488.

https://doi.org/10.1183/13993003.01488-2017

Liu, X., Lewis, J. J., Zhang, H., Lu, W., Zhang, S., Zheng, G., ... Fielding, K. L. (2015). Effectiveness of
Electronic Reminders to Improve Medication Adherence in Tuberculosis Patients: A ClusterRandomised Trial. PLoS Medicine, 12(9), 1-18. https://doi.org/10.1371/journal.pmed.1001876

Mohammed, S., Glennerster, R., \& Khan, A. J. (2016). Impact of a Daily SMS Medication Reminder System on Tuberculosis Treatment Outcomes : A Randomized Controlled Trial, 11, 1-14. https://doi.org/10.7910/DVN/HVJ2CM.Funding

Molton, J. S., Pang, Y., Wang, Z., Qiu, B., Wu, P., RahmanShepherd, A., ... Paton, N. I. (2016). Prospective single-arm interventional pilot study to assess a smartphone-based system for measuring and supporting adherence to medication. BMJ Open, 6(12). https://doi.org/10.1136/bmjopen-2016014194

Nhavoto, J. A., Gronlun, A., \& Klein, G. O. (2017). Mobile health treatment support intervention for HIV and tuberculosis in Mozambique: Perspectives of patients and healthcare workers. Plos One, 1-13. https://doi.org/10.1371/journal.pone.0176051

Oren, E., Bell, M. L., Garcia, F., Perez-Velez, C., \& Gerald, L. B. (2017). Promoting adherence to treatment for latent TB infection through mobile phone text messaging: Study protocol for a pilot randomized controlled trial. Pilot and Feasibility Studies, 3(1), 1-9. https://doi.org/10.1186/s40814-017-01289

Orrell, C., Cohen, K., Mauff, K., Bangsberg, D. R., Maartens, G., \& Wood, R. (2015). A Randomized Controlled Trial of Real-Time Electronic Adherence Monitoring With Text Message Dosing Reminders in People Starting First-Line Antiretroviral Therapy. Jaids-Journal of Acquired Immune Deficiency Syndromes, 70(5), 495-502. https://doi.org/10.1097/QAI.000000000000077 0

Sinkou, H., Hurevich, H., Rusovich, V., Zhylevich, L., Falzon, D., De Colombani, P., ... Skrahina, A. (2017). Video-observed treatment for tuberculosis patients in Belarus: Findings from the first programmatic experience. European Respiratory Journal, 49(3), 1-3. https://doi.org/10.1183/13993003.02049-2016

Van Der Kop, M. L., Memetovic, J., Patel, A., Marra, F., Sadatsafavi, M., Hajek, J., ... Lester, R. T. (2014). The effect of weekly text-message communication on treatment completion among patients with latent tuberculosis infection: Study protocol for a randomised controlled trial (WelTel LTBI). BMJ Open, 4(4), 1-9. https://doi.org/10.1136/bmjopen-2013-004362

Vasbinder, E. C., Goossens, L. M. A., Rutten-Van Mölken, M. P. M. H., De Winter, B. C. M., Van Dijk, L., Vulto, A. G., ... Van Den Bemt, P. M. L. A. (2016). EMonitoring of Asthma Therapy to Improve Compliance in children (e-MATIC): A randomised controlled trial. European Respiratory Journal, 48(3), 758-767. https://doi.org/10.1183/13993003.01698-2015 
D. U. SHOLIKHAH, ET AL.

WHO. (2016). WHO | Global Tuberculosis Report 2016. Who 2016, (1), 1-204. https://doi.org/ISBN 9789241565394
World Health Organization. (2017). Global Tuberculosis Report 2017. World Health Organizacion Report 2017. https://doi.org/WHO/HTM/TB/2017.23 